\title{
Commentary: Chemokines in Prediabetes and Type 2 Diabetes: A Meta-Analysis
}

\author{
Jie Wei ${ }^{*}$ \\ Department of Hematology, People's Hospital of Baise, Baise, China
}

Keywords: letter, chemokines, prediabetes, diabetes, meta

OPEN ACCESS

Edited by:

Julio Villena,

CONICET Centro de Referencia para Lactobacilos (CERELA), Argentina

Reviewed by: Guillermo Emilio Marcial, CONICET Centro de Referencia para Lactobacilos (CERELA), Argentina

*Correspondence: Jie Wei Weijie20212021@126.com

Specialty section:

This article was submitted to Nutritional Immunology, a section of the journal

Frontiers in Immunology

Received: 23 June 2021

Accepted: 26 August 2021

Published: 16 September 2021

Citation:

Wei J (2021) Commentary: Chemokines in Prediabetes and Type 2 Diabetes: A Meta-Analysis.

Front. Immunol. 12:729702. doi: 10.3389/fimmu.2021.729702

\section{A Commentary on}

Chemokines in Prediabetes and Type 2 Diabetes: A Meta-Analysis By Pan X, Kaminga AC, Wen SW and Liu A (2021). Front. Immunol. 12:622438. doi: 10.3389/fimmu.2021.622438

We read the paper by Pan et al. (1) with interest. The authors report a meta-analysis to summarize the results of previous studies on the association between the chemokines system and type 2 diabetes (T2DM)/prediabetes (PDM). They concluded that progression of T2DM may be associated with elevated concentrations of chemokines. After carefully reading, I wish to put forth the following suggestions.

References 12 (Sindhu et al., 2017) (2) and 102 (Sindhu et al., 2016) (3) in Table 1 were created by the same author team, with the characteristics (Male gender, BMI, and Mean age) inserted wrongly. This wrong insertion of the data would affect the credibility of the meta-analysis's final results. I recommend that the authors (1) must include both works (Sindhu's papers) in the metaanalysis but a previous correction and reliable checking of the data insertion is required.

Not only in Table 1 but also in Figure 1. In this figure, every insertion of the "Sindhu 2017" was wrong, instead "Sindhu 2017" should have been inserted as "Sindhu 2016". Furthermore, in "type: CCL2", the data for "Sindhu 2016" was inserted with 13 diabetic and 25 non-diabetic individuals when it must have been 53/72 or 23/24, depending on either Sindhu 2017 or 2016. Also, in "type: CCL11" and "type: CCL4" must be inserted both work's data $(2,3)$.

Due to these mistakes, I recommend to the editor to request a completely new evaluation of all data setting, the correction of tables and figures, and between the data insertion and wrong data typing. Mistakes in the data typing are not allowed if the credibility of the meta-analysis results is desired. 


\section{AUTHOR CONTRIBUTIONS}

The author confirms being the sole contributor of this work and has approved it for publication.

\section{REFERENCES}

1. Pan X, Kaminga AC, Wen SW, Liu A. Chemokines in Prediabetes and Type 2 Diabetes: A Meta-Analysis. Front Immunol (2021) 12:622438. doi: 10.3389/ fimmu.2021.622438

2. Sindhu S, Akhter N, Arefanian H, Al-Roub AA, Ali S, Wilson A, et al. Increased Circulatory Levels of Fractalkine (CX3CL1) Are Associated With Inflammatory Chemokines and Cytokines in Individuals With Type-2 Diabetes. J Diabetes Metab Disord (2017) 16(1):15. doi: 10.1186/s40200017-0297-3

3. Sindhu S, Akhter N, Shenouda S, Wilson A, Ahmad R. Plasma Fetuin-A/ Alpha 2-HS-Glycoprotein Correlates Negatively With Inflammatory Cytokines, Chemokines and Activation Biomarkers in Individuals With Type-2 Diabetes. BMC Immunol (2016) 17:33. doi: 10.1186/s12865-016$0171-y$

\section{ACKNOWLEDGMENTS}

Department of Hematology, People's Hospital of Baise, Baise, China.

Conflict of Interest: The author declares that the research was conducted in the absence of any commercial or financial relationships that could be construed as a potential conflict of interest.

Publisher's Note: All claims expressed in this article are solely those of the authors and do not necessarily represent those of their affiliated organizations, or those of the publisher, the editors and the reviewers. Any product that may be evaluated in this article, or claim that may be made by its manufacturer, is not guaranteed or endorsed by the publisher.

Copyright (c) 2021 Wei. This is an open-access article distributed under the terms of the Creative Commons Attribution License (CC BY). The use, distribution or reproduction in other forums is permitted, provided the original author(s) and the copyright owner(s) are credited and that the original publication in this journal is cited, in accordance with accepted academic practice. No use, distribution or reproduction is permitted which does not comply with these terms. 